\title{
EMPREGABILIDADE PROFISSIONAL: O SECRETARIADO EXECUTIVO EM FOCO NA AMAZÔNIA SETENTRIONAL
}

\section{PROFESSIONAL EMPLOYABILITY: EXECUTIVE SECRETARIAT IN FOCUS ON NORTHERN AMAZON}

\section{Antônia Aline Rodrigues}

Graduação em Secretariado Executivo pela Universidade Federal de Roraima - UFRR, Roraima (Brasil). Secretaria de Diretor pela Fundação Estadual do Meio Ambiente e Recursos Hídricos FEMARH-RR, Roraima (Brasil). E-mail: aline20-rodrigues@ hotmail.com

\section{Jaqueline Silva Rosa}

Mestrado em Administração pela Universidade do Vale do Rio dos Sinos - UNISINOS, Rio Grande do Sul (Brasil). Professora de Administração pela Universidade Federal de Roraima UFRR, Roraima (Brasil). E-mail: jaqueline.rosa@ufrr.br

\section{Geórgia Patricia Silva Ferko}

Doutorado em Políticas Públicas pela Universidade Federal do Maranhão - UFMA, Maranhão (Brasil). Professora pela Universidade Federal de Roraima - UFRR, Roraima (Brasil).

E-mail: geoufpe@yahoo.com.br

\section{Marta Margareth Braid Melo}

Mestrado em Administração pela Fundação Universidade Regional de Blumenau - FURB, Santa Catarina (Brasil). Professora Universidade Federal de Roraima - UFRR, Roraima (Brasil).

E-mail: martabraidmelo@hotmail.com

Data de recebimento do artigo: $11 / 03 / 2016$ 


\section{EMPREGABILIDADE PROFISSIONAL: O SECRETARIADO EXECUTIVO EM FOCO NA AMAZÔNIA SETENTRIONAL}

\section{RESUMO}

Este artigo tem como objetivo verificar as dificuldades encontradas por profissionais de Secretariado Executivo, concernentes a sua inserção no mercado de trabalho na cidade de Boa Vista, estado de Roraima, na Amazônia setentrional. Para tanto, fez-se um trabalho de abordagem qualitativa, com entrevistas em profundidade com profissionais de Secretariado Executivo e gestores de Recursos Humanos. Após a análise de dados, verificou-se que as dificuldades de inserção no mercado de trabalho para esses profissionais são as seguintes: escassez de vagas no setor privado em Roraima; baixa remuneração à profissão; ausência de reconhecimento e desconhecimento das atribuições por parte dos gestores, os quais indicam a polivalência como garantia de empregabilidade aos profissionais de Secretariado Executivo. Vê-se uma lacuna nas duas visões, pois para os profissionais de Secretariado Executivo, só a polivalência não é garantia de empregabilidade.

Palavras-chave: Secretariado Executivo. Empregabilidade. Mercado de trabalho. 


\title{
PROFESSIONAL EMPLOYABILITY: EXECUTIVE SECRETARIAT IN FOCUS ON NORTHERN AMAZON
}

\begin{abstract}
This article aims to determine the difficulties encountered by the Executive Secretary of professionals concerning their integration in the labor market in the city of Boa Vista, Roraima, in the northern Amazon. Therefore, it was a qualitative study, with in-depth interviews with professionals from the Executive Secretary and Human Resources managers. After data analysis, it was found that the insertion difficulties in the labor market for these professionals are: shortage of jobs in the private sector in Roraima; low pay to the profession; lack of recognition and lack the powers of managers, which indicate the versatility and employability security for Executive Secretariat professionals. Seeing a gap is seen in two views as to the professionals of the Executive Secretariat, only the versatility is not employment guarantee.
\end{abstract}

Key-words: Executive Secretariat. Employability. Job market. 


\section{INTRODUÇÃO}

O mercado competitivo exige que os profissionais tenham, além do conhecimento técnico e específico, competências comportamentais que promovam integral formação, com busca constante de atualização para acompanhar as mudanças que o mercado propõe. Em decorrência dessa alta competitividade, o profissional de Secretariado Executivo (SE), para melhorar sua empregabilidade, deve acompanhar as alternâncias e adequar seu perfil às exigências do mercado de trabalho. De acordo com Veiga (2007), aquele profissional que apenas executava as ordens deu lugar a um profissional que tem consciência da grande importância do cargo nas organizações. As responsabilidades aumentaram e, com isso, surgiu a necessidade de se aperfeiçoar para acompanhar as mudanças da empresa.

A inserção dos profissionais no mercado de trabalho remete à capacitação e à percepção que estes deverão possuir de forma a vislumbrar oportunidades apresentadas pelas organizações, aumentando suas chances de empregabilidade. Segundo Carvalho (2002), compreende-se por empregabilidade todo aquele profissional que apresenta qualidade empregável, representando, desta forma, um conceito dinâmico concernente ao mundo do trabalho, que expressa tudo quanto o indivíduo deve ter para sua profunda e imprescindível capacidade de se adaptar e se enquadrar nesse mercado globalizado.

Segundo Saviani (1997), a alta taxa de empregabilidade depende de alguns fatores, como criatividade, empatia, flexibilidade, extroversão, bom senso, liderança, iniciativa, inteligência emocional e cultura global. Vê-se que tais fatores estão para além das capacidades técnicas aprimoradas na qualificação dos profissionais. A partir desse cenário, no qual os profissionais buscam empregabilidade, o profissional de Secretariado, para acompanhar o ritmo das alterações, deve desenvolver competências técnicas e humanas visando ao crescimento e aperfeiçoamento para se distinguir no mercado de trabalho.

Criatividade, inovação, iniciativa e liderança são algumas das várias palavras de ordem empregadas no contexto das organizações. Nesse sentido, cada vez mais o assunto competência é discutido, seja na dimensão individual (Mcclelland, 1973; Zarifian, 1996; Le Boterf, 2001; Fleury e Fleury, 2001 como citado em Fleury e Sarsur, 
2007) seja na dimensão coletiva (Leonard-Barton, 1992; Nordhaug \& Grönhaug, 1994; Ruas, 2000; Becker, 2004; Weick, 1993; Weick \& Roberts, 1993; Sandberg, 1996; Zarifian, 2001; Lê Boterf, 2003 e Boreham, 2004 como citado em Rosa, 2007).

A discussão acerca das competências ampara de forma direta e, proporcionalmente, a empregabilidade. Logo, os profissionais da contemporaneidade devem sobressair-se em aspectos comportamentais, não apenas em habilidades de ordem técnica. Nesse sentido, a questão de pesquisa que norteia este estudo é: Quais as dificuldades dos profissionais de Secretariado Executivo no que diz respeito à inserção no mercado de trabalho na cidade de Boa Vista - RR?

De forma a responder à questão de pesquisa proposta, o objetivo geral deste trabalho é verificar as dificuldades dos profissionais de Secretariado Executivo no que diz respeito à inserção no mercado de trabalho. Em vista disso, têm-se como objetivos específicos: a) conhecer as competências do profissional de Secretariado Executivo a partir da percepção deles mesmos; b) descrever a satisfação e reconhecimento do profissional de SE; c) conhecer as dificuldades de inserção do mercado de trabalho; d) identificar o perfil e competências do profissional de SE na percepção dos gestores de $\mathrm{RH}$; e) verificar as oportunidades e os desafios para o profissional de SE e f) descrever a importância do profissional de secretariado para o mercado de trabalho.

Para tanto, este artigo está estruturado em cinco seções. Na primeira seção, apresenta-se a temática de trabalho e objetivos; na segunda seção, tem-se o referencial teórico; na terceira seção, apresenta-se a metodologia do estudo, com classificação da pesquisa, população-alvo e técnicas de coleta e análise de dados. Na quarta seção, apresentam-se os resultados e discussão do estudo. Em seguida, há as considerações finais seguidas das referências.

\section{REFERENCIAL TEÓRICO}

\section{As exigências do mercado de trabalho}

De acordo com Bertolino (2002), o ambiente de trabalho é competitivo e seletivo para o profissional, fazendo com que o crescimento e os resultados de uma organização sejam alcançados à custa das competências pessoais e não só por habilidades técnicas. Com isso, a sociedade procura profissionais envolvidos com o todo e preocupados com Revista de Gestão e Secretariado-GeSec, São Paulo, v. 7, n. 3, p 66-95, set./dez. 2016. 
resultados satisfatórios à organização, uma vez que o aumento da concorrência e da competição globalizada é uma realidade notável no mundo do trabalho. Além disso, as relações de trabalho foram inovadas totalmente pela mundialização, tornando mais complexo o papel destinado a cada profissional dentro das organizações (Fachini, 2009).

Nesse sentido, Arruda (2010) indica que o conhecimento é uma das capacidades fundamentais no mercado de trabalho, para que os profissionais de todos os níveis possam atingir seus objetivos de crescimento, como conseguir uma promoção, ou até mesmo uma nova oportunidade no mundo do trabalho.

Neiva e D’Elia (2005) apresentam um quadro com as mudanças das exigências do mercado. Observe quadro 1 a seguir:

Quadro 1: Perfil do profissional no geral.

\begin{tabular}{|c|c|c|c|}
\hline Década de 70 & Década de 80 & Década de 90 & Século XXI \\
\hline $\begin{array}{l}\text { A experiência é uma } \\
\text { ferramenta usada no } \\
\text { comando. }\end{array}$ & $\begin{array}{l}\text { O grau de escolaridade é sua } \\
\text { ferramenta de comando. }\end{array}$ & $\begin{array}{l}\text { Sua performance é } \\
\text { sua ferramenta de } \\
\text { comando. }\end{array}$ & $\begin{array}{l}\text { O profissional e sua } \\
\text { equipe são as } \\
\text { ferramentas do sucesso } \\
\text { dele e de outros. }\end{array}$ \\
\hline Acomodado. & Confiante. & Curioso. & Estudioso. \\
\hline Dependente. & Político. & Independente. & $\begin{array}{l}\text { Tem visão global das } \\
\text { coisas. }\end{array}$ \\
\hline Resiste a mudanças. & Ajusta-se às mudanças. & Gera mudanças. & Lidera mudanças. \\
\hline Procura ser carreirista. & Procura ser cooperador. & $\begin{array}{l}\text { Procura } \\
\text { facilitador. }\end{array}$ & ser criativo. \\
\hline $\begin{array}{l}\text { Seu salário é } \\
\text { determinado pela } \\
\text { empresa. }\end{array}$ & $\begin{array}{l}\text { Seu salário é negociado pela } \\
\text { empresa. }\end{array}$ & $\begin{array}{l}\text { Seu salário é } \\
\text { conquistado pela } \\
\text { importância do seu } \\
\text { trabalho. }\end{array}$ & $\begin{array}{l}\text { Seu resultado é } \\
\text { conquistado pelo } \\
\text { esforço de seu } \\
\text { trabalho, bem como de } \\
\text { sua equipe. }\end{array}$ \\
\hline $\begin{array}{l}\text { Seu reconhecimento é } \\
\text { fruto da experiência } \\
\text { profissional. }\end{array}$ & $\begin{array}{l}\text { Seu conhecimento é baseado } \\
\text { na teoria acadêmica. }\end{array}$ & $\begin{array}{l}\text { Seu conhecimento é } \\
\text { fruto da aplicação } \\
\text { prática da teoria. }\end{array}$ & $\begin{array}{l}\text { Seu conhecimento é } \\
\text { fruto do aprendizado } \\
\text { contínuo. }\end{array}$ \\
\hline
\end{tabular}

Fonte: Neiva e D'Elia (2005 p. 24).

O exposto pelo Quadro 1 traduz a evolução que o mercado de trabalho apresentou, demonstrando que, ao longo do tempo, as exigências passaram a focar nas atitudes dos profissionais e no conhecimento destes. De acordo com D'Elia (1997), o mercado de Revista de Gestão e Secretariado-GeSec, São Paulo, v. 7, n. 3, p 66-95, set./dez. 2016. 
trabalho procura profissionais que despertam para um novo contexto e, por isso, se destacam dos demais. O profissional necessita, por conseguinte, estar capacitado para enfrentar as exigências do concorrido mercado de trabalho, principalmente no que diz respeito aos conhecimentos específicos relacionados a sua profissão. Mas, como afirma Minarelli (1995), não basta que a pessoa possua apenas determinada formação profissional, já que o mercado pede destaque, diferencial imprescindível para que esse profissional seja empregável.

Para Veiga (2007), o profissional que obedecia a ordens deu lugar a um novo profissional, que tem consciência do valor do cargo dentro das empresas, pois, com o aumento das responsabilidades, surge a necessidade de aperfeiçoamento, fator determinante para acompanhar as transformações. Diante da atual concorrência do mercado, os profissionais devem se adaptar a essas exigências, construindo um perfil que o mercado de trabalho deseja, tornando-se um profissional com múltiplas habilidades e competências, aliado a características como formação, ética, conhecimento e capacidade de se ajustar às diferentes mudanças, para que venha a ser um profissional empregável.

Observa-se que as empresas desejam mais do que competências técnicas; principalmente, habilidades humanas e conceituais, que devem ser desenvolvidas e aprimoradas, para que os profissionais possam ter melhores colocações no mercado de trabalho e, consequentemente, uma empregabilidade maior, o que as leva a buscar profissionais que agreguem valor à organização. E, em função de um mercado altamente competitivo, escolhem os melhores candidatos para fazer parte do quadro de trabalho, exatamente aqueles que apresentam habilidades e competências como: qualificação, criatividade, inovação, flexibilidade e capacidade para trabalhar em equipe. O obstáculo não é apenas conseguir se inserir no mercado de trabalho, mas garantir a empregabilidade, ou seja, ser um profissional empregável.

\section{Empregabilidade: o desafio aos profissionais}

A empregabilidade é um termo que está sendo amplamente debatido e pode ser compreendida como as ações executadas pelas pessoas para desenvolver habilidades e buscar conhecimentos, com o intuito de conseguir uma colocação no mercado de trabalho, seja ele formal ou informal. Por meio dela, é possível tornar-se administrador 
da própria carreira, sendo responsável pelos seus ganhos e perdas (Nascimento et al., 2005).

Conforme Carvalho (2002) compreende-se por empregabilidade todo aquele profissional que apresenta qualidade empregável, representando, desta forma, um conceito dinâmico concernente ao mundo do trabalho, que expressa tudo quanto o indivíduo deve ter para sua profunda e imprescindível capacidade de se adaptar e se enquadrar nesse mercado globalizado. Hilsdorf (2008) afirma que a empregabilidade é um tema bastante dinâmico, e a lista de pré-requisitos necessários para ser desejado pelo mercado de trabalho cresce de uma forma contínua, uma vez que as competências essenciais se tornam mais extensas, à medida que o tempo passa. Essa situação obriga os profissionais a construir, a apresentar e a ampliar os conhecimentos gerados no decorrer da progressão profissional.

Nesse âmbito, o conhecimento é o principal aliado e essencial para os profissionais, que têm de aprender continuamente. Peres (2005) afirma que os profissionais do século XXI precisam ter a autêntica formação naquilo que se predispõem a trabalhar ou desempenhar, bem como possuir uma educação geral. Vê-se que podem ser pontuados vários aspectos que auxiliam a empregabilidade a ser sustentável. Minarelli (1995) afirma que os profissionais precisam se reciclar periodicamente, para que possam manter seus conhecimentos atualizados e desenvolver habilidades para enfrentar as mudanças do mercado de trabalho, a fim de aumentar a sua empregabilidade e desenvolver sua carreira, construindo bases próprias.

Diante dessa nova realidade, o profissional necessita agregar valor a si mesmo, para se tornar empregável. Atitudes, como proatividade, comprometimento, criatividade e flexibilidade representam diferencial no mercado de trabalho. E, com todos esses requisitos, o profissional deve buscar qualificação constantemente, para que tenha empregabilidade, seguindo uma preparação prévia de carreira, desenvolvendo habilidades e conhecimentos necessários nas diferentes áreas do mercado de trabalho. Todavia, pode acontecer que ele apresente insegurança em relação a sua empregabilidade, a qual se assenta em fatores como: competências, habilidades, comportamentos e conhecimentos adequados ao seu perfil de atuação.

Fatores de manutenção da empregabilidade

Revista de Gestão e Secretariado-GeSec, São Paulo, v. 7, n. 3, p 66-95, set./dez. 2016. 
As mudanças frequentes no mercado de trabalho e na sociedade em geral exigem dos profissionais uma enorme capacidade de adaptação à evolução das exigências do mercado de trabalho no mundo das profissões. Baggio et al. (2005) apontam quatro fatores considerados essenciais à manutenção do nível de empregabilidade, atualmente: adaptar-se às mudanças, perfil adequado à profissão, rede de relacionamentos e educação continuada.

De fato, as mudanças na realidade do mundo do trabalho estão acontecendo; e isso se deve, em parte, às exigências de mercado e às alterações de perfis de profissionais que, por sua vez, devem adaptar-se a essas mudanças. E, para os profissionais capacitados e visionários, estes serão agentes de mudança, extraindo delas as suas principais vantagens competitivas (Porter, 1989). Algumas habilidades são fundamentais ao profissional que deseja sucesso em ambientes de mudança, destacandose entre elas a adaptação e flexibilidade a novos cenários, visão de futuro, bom relacionamento interpessoal e autoconfiança em sua qualificação, garantindo a este profissional melhores condições para se adaptar às transformações e usufruir de seus benefícios, amenizando o impacto dos seus pontos fracos e de algumas dificuldades (Baggio et al., 2005).

Os seis pilares que sustentam a empregabilidade são (Minarelli, 1995): a adequação vocacional, competência profissional, idoneidade, saúde física e mental, reserva financeira e fontes alternativas e relacionamentos. A união de todos esses requisitos proporciona segurança ao profissional, confere empregabilidade, isto é, a capacidade de gerar trabalho, de trabalhar e ganhar. O autor indica que esses pilares necessitam estar conectados e articulados entre si uma vez que a articulação entre esses aspectos gera a sinergia necessária à empregabilidade.

As frequentes mudanças que ocorrem no ambiente de trabalho e na sociedade em geral exigem dos profissionais uma enorme capacidade de adaptação. A atribuição desses fatores para manter a empregabilidade estabelece no profissional a capacidade de superar a competitividade que se apresenta atualmente e são essenciais para manutenção do nível da empregabilidade.

Revista de Gestão e Secretariado-GeSec, São Paulo, v. 7, n. 3, p 66-95, set./dez. 2016. 


\section{Profissional de Secretariado Executivo e suas competências}

Vive-se em um mundo de mudanças constantes, que exige do profissional atualização para atender as necessidades do mercado (Minarelli, 1995). Para obter um amplo espaço no mercado de trabalho, o profissional de Secretariado Executivo deve se adaptar às exigências do mercado. Devido ao seu desempenho e sua aptidão de pensar com estratégia, esse profissional atingiu um novo patamar, no qual foram delegadas responsabilidades e, a partir daí, assumiu cargos de gestão.

Natalense (1998) afirma que o secretário está assumindo uma postura profissional de empreendedor, pois é criativo, tem iniciativa e é capaz de tomar decisões, com ideias práticas e inovadoras. Bortolotto e Willers (2005) apresentam que o profissional de Secretariado Executivo não está limitado às tarefas de rotina de um ambiente organizacional; as autoras ainda indicam que embora haja muita relevância nas competências técnicas, as competências comportamentais são fundamentais e muito mais densas no dia a dia deste profissional.

Nesse sentido, Neiva e D' Elia (2005) reforçam essa afirmativa ao pontuar que ao mesclar competências técnicas e comportamentais, o profissional de SE reúne o fazer e o assessorar, escolhendo ferramentas que exercitam habilidades de relacionamento, comunicação, administração de conflitos e acompanhamento de objetivos, ampliando, assim, a dimensão do seu fazer. A profissão exige “[...] conhecimentos gerais e gerenciamento de processos visando à solução de problemas de um mercado de trabalho, cuja influência na sociedade, cada vez mais complexa, não permite que esse profissional invista em ser apenas um escriturário solucionador de simples problemas do dia a dia." (Bianchi, Alvarenga \& Bianchi, 2003, p. 3). As discussões circundam desde o que fazer até o que seja o profissional secretário (Hoeller, 2006; Nonato Júnior, 2002; Pringle, 1989; Thurloway, 2004).

Sendo assim, o profissional de Secretariado Executivo deve ter formação acadêmica específica, trabalhar com criatividade, flexibilidade, ter excelente comunicação e relacionamento interpessoal, além de assessorar com qualidade os executivos e estar em constante atualização, ampliando suas competências e seu campo de inserção no mercado de trabalho. De acordo com Castelo (2007), a profissão de Secretário Executivo passou por três grandes transformações que deram novas direções à profissão e ao seu exercício: a era da Qualidade, a era da Informática e a era da 
Competência. Essas mudanças deram ao profissional um leque de novas responsabilidades e o compromisso de apresentar resultados visíveis para a organização.

Neiva e D'Elia (2005) apresentam um quadro comparando o perfil do profissional de secretariado.

\section{Quadro 2: Perfil do profissional de Secretariado}

\begin{tabular}{|l|l|l|}
\hline Ontem & Hoje & Futuro \\
\hline $\begin{array}{l}\text { Formação dispersiva, } \\
\text { autodidatismo. }\end{array}$ & $\begin{array}{l}\text { Existência de cursos específicos } \\
\text { para formação. }\end{array}$ & $\begin{array}{l}\text { Amadurecimento profissional - } \\
\text { código de ética. }\end{array}$ \\
\hline $\begin{array}{l}\text { Falta de qualquer requisito para o } \\
\text { aprimoramento. }\end{array}$ & $\begin{array}{l}\text { Cursos de reciclagem e de } \\
\text { conhecimentos peculiares. }\end{array}$ & $\begin{array}{l}\text { Constante aprimoramento e } \\
\text { desenvolvimento contínuo. }\end{array}$ \\
\hline $\begin{array}{l}\text { Ausência de política para } \\
\text { recrutamento de seleção. }\end{array}$ & $\begin{array}{l}\text { Exigência de qualificação e } \\
\text { definição de atribuições e plano } \\
\text { de carreira. }\end{array}$ & $\begin{array}{l}\text { Visão holística e trabalho em } \\
\text { equipe, consciência profissional. }\end{array}$ \\
\hline $\begin{array}{l}\text { Organizações burocráticas com } \\
\text { tarefas isoladas. }\end{array}$ & $\begin{array}{l}\text { Organizações participativas, } \\
\text { tarefas definidas, trabalho com } \\
\text { qualidade, criatividade e e } \\
\text { participação. }\end{array}$ & $\begin{array}{l}\text { Organizações empreendedoras, } \\
\text { trabalho em equipe, visão global, } \\
\text { metodologia flexível, divisão de } \\
\text { responsabilidade. }\end{array}$ \\
\hline $\begin{array}{l}\text { Secretária como função. } \\
\text { Secretária como profissão. }\end{array}$ & $\begin{array}{l}\text { Secretária com reconhecimento } \\
\text { profissional e comprometida com } \\
\text { resultados. }\end{array}$ \\
\hline
\end{tabular}

Fonte: Neiva e D'Elia (2005 p. 25).

No quadro 2, sobre o perfil do secretário executivo, Neiva e D’Elia (2005) asseguram que somente um profissional com uma visão holística, trabalho em equipe, amadurecimento, entre outros, atende de forma satisfatória o mercado de trabalho e suas múltiplas exigências. As autoras apresentam as características que eram exigidas desse profissional no passado, em contraposição às exigências atuais. "De forma qualitativa, a secretária está inserida no processo gerencial das empresas, como uma profissional vital, para trabalhar ao lado do poder decisório, otimizando resultados em times, projetos, virtualmente e nas múltiplas opções que o mercado de trabalho oferece a todos os profissionais" (Neiva \& D’Elia, 2005, p. 20). Percebe-se a transfiguração das competências desenvolvidas pelos profissionais de SE, uma vez que o mercado é global. Nesse sentido, Bianchi, Alvarenga e Bianchi (2003, p.7) acrescentam que 
[...] a tendência do mercado de trabalho é exigir do profissional conhecimentos generalizados e competências múltiplas que transcendam as fronteiras do país no qual vive, e esta exigência é ainda maior quando o enfoque é para profissões como o secretariado [...].

Castelo (2007) aborda sobre essas qualificações do perfil do profissional de SE: assessor, gestor, empreendedor e consultor. O profissional de Secretariado, como assessor, precisa ter conhecimentos das diversas áreas de negócios e administrativas, assim desempenhando práticas de comunicação e de liderança. Com relação a atuar como gestor, ele precisa desenvolver suas atribuições com qualidade e com assertividade, aprimorando a otimização de resultados por meio de planejamento, organização e controle de atividades, pois, para ser empreendedor, esse profissional deve ser: ativo, criativo, inovador, negociador, além de outras competências que visam ao constante aperfeiçoamento nas diversas áreas, implantando ideias que potencializem o alcance dos objetivos da empresa. Como consultor, o secretário executivo desempenha sua função, envolvido com o todo da organização, realizando as alterações necessárias, visando a alcançar os objetivos da empresa e do executivo.

Para Bianchi, Alvarenga e Bianchi (2003), o Secretariado Executivo é uma das áreas que mais cresce no mercado, motivo pelo qual o profissional tem de permanecer atento às exigências que ele demanda e sempre estar em sintonia com os padrões referentes a sua área de atuação. Bond e Oliveira (2009, p. 25) contribuem: “Com as mudanças que caracterizam o cenário mundial, o profissional precisa adaptar-se ao mercado e, mais ainda, à empresa na qual está atuando".

A Lei 7.377 , de 30 de setembro de 1985, a qual fora complementada pela Lei 9.261, de 10 de janeiro de 1996, estabelece os pré-requisitos para a diplomação em curso superior de Secretariado e indica as competências desses profissionais, nas seguintes áreas: planejamento, organização e direção de serviços de secretaria; assistência e assessoramento direto a executivos; coleta de informações para a consecução de objetivos e metas de empresas; redação de textos profissionais especializados, inclusive em idioma estrangeiro; interpretação e sintetização de textos e documentos taquigrafia de ditados, discursos, conferências, palestras de explanações, inclusive em idioma estrangeiro; versão e tradução em idioma estrangeiro, para atender às necessidades de comunicação da empresa; registro e distribuição de expedientes e outras tarefas correlatas; orientação da avaliação e seleção da correspondência para fins de encaminhamento à chefia; e conhecimentos protocolares (planalto.gov.br, 2014).

Revista de Gestão e Secretariado-GeSec, São Paulo, v. 7, n. 3, p 66-95, set./dez. 2016. 
Observa-se a complexidade de competências que o profissional necessita desenvolver na sua capacitação e que possa lhe garantir inserção no mundo do trabalho. Maçaneiro e Kuhl (2013) já indicaram que grande parte das publicações em Secretariado Executivo volta-se à empregabilidade, uma vez que há a preocupação de oportunizar densidade à discussão do campo de trabalho deste profissional, bem como firmá-lo enquanto área de conhecimento.

\section{METODOLOGIA}

Tendo como objetivo geral verificar as dificuldades encontradas por profissionais de Secretariado Executivo no mercado de trabalho, este estudo realizou pesquisa de abordagem qualitativa, a qual proporciona maior profundidade e interpretação das singularidades das ações e posturas das pessoas (Oliveira, 2002). Portanto, a abordagem qualitativa foi a mais adequada para compreender, a partir da percepção dos profissionais de SE, as dificuldades de inserção no mercado de trabalho. No que se refere à população-alvo desta pesquisa, essa foi centrada nos profissionais de Secretariado Executivo, da cidade de Boa Vista (Roraima), assim como gestores de Recursos Humanos (RH).

Para tanto, foram mantidos 23 contatos com profissionais de SE e 6 com os gestores de $\mathrm{RH}$, mas 12 profissionais e 4 gestores concordaram em participar da pesquisa. Aplicou-se amostragem não probabilística por conveniência, por meio da qual, segundo Prodanov (2009, p. 109), “[...] o pesquisador seleciona os elementos a que tem acesso".

Quanto à técnica de coleta, empregou-se entrevista em profundidade, guiada por um roteiro de perguntas abertas, firmadas a partir do referencial teórico. Os sujeitos de pesquisa foram mencionados como: profissionais de SE A até L; e os gestores de RH 1 até 4 .

Quanto ao perfil dos 12 entrevistados, 10 são de organizações públicas e dois de organizações privadas, sendo que 11 dos profissionais de SE são do sexo feminino e 1 do sexo masculino. Em relação à idade, constatou-se que seis entrevistados têm entre 21 a 30 anos, e os outros seis têm entre 31 a 40 anos. No que diz respeito à função, percebeu-se que nove dos entrevistados atuam como Secretário Executivo e três como Revista de Gestão e Secretariado-GeSec, São Paulo, v. 7, n. 3, p 66-95, set./dez. 2016. 
Assistente Administrativo. Viu-se que seis dos entrevistados são graduados; e, cinco tem pós-graduação.

Já quanto aos quatro gestores participantes, todos são do sexo feminino, sendo que três trabalham em organizações públicas e uma em organização privada. Em relação à idade, observou-se que um dos entrevistados tem acima de 40 anos, os outros dois encontram-se em uma faixa etária de 21 a 30 anos e, por fim, um na faixa de 31 a 40 anos. Observou-se que os entrevistados possuem experiência na função há mais de quatro anos, no mercado de trabalho, e que todos, em relação à escolaridade, têm pósgraduação.

Foi empregada a análise de conteúdo, que segundo Roesch (2005), proporciona ao pesquisador entender e capturar a perspectiva dos respondentes. Neste estudo, por considerar sujeitos distintos, ou seja, os profissionais de SE e o gestor de $\mathrm{RH}$, o roteiro de perguntas foi estruturado a partir das categorias previamente definidas, a partir do referencial teórico, quais sejam: a) as competências do profissional de Secretariado Executivo; b) satisfação e reconhecimento do profissional; c) dificuldades de inserção do mercado de trabalho; d) perfil e competências do profissional de SE na percepção dos gestores de $\mathrm{RH}$; e) oportunidade e desafio para o profissional de SE e f) a importância do profissional de Secretariado para o mercado de trabalho.

\section{ANÁLISE E DISCUSSÃO DOS RESULTADOS}

\section{As competências do profissional de Secretariado Executivo}

Como já pontuado por alguns autores na discussão teórica (Minarelli, 1995; Baggio et al., 2005; Chiavenato, 2002), as competências devem ser o foco principal de todo e qualquer profissional, para uma boa colocação no mercado de trabalho. Nesse sentido, algumas perguntas do roteiro de entrevistas versaram sobre as competências que contribuem nos resultados da organização.

$\mathrm{Na}$ primeira questão, perguntou-se acerca das competências desejadas. A entrevistada A declarou que o profissional de SE

precisa desenvolver e demonstrar as competências [...], tais como a eficiência, efetividade [...] flexibilidade, manter o foco, o objetivo nos resultados [...]

e acrescenta ainda que ele deve ter

Revista de Gestão e Secretariado-GeSec, São Paulo, v. 7, n. 3, p 66-95, set./dez. 2016. 
as qualidades inerentes a todo profissional bem-sucedido, como respeito, ética, know-how, inteligência emocional, entre outras.

A entrevistada B relatou que o profissional de Secretariado Executivo "precisa ser proativo, tem que ser organizado, extrovertido e ter bastante autodisciplina".

As entrevistadas C, D, G e I pontuam as seguintes competências: empreendedor, criativo, delegação de tarefas, ter iniciativa, inovador, comunicação e também competências técnicas e humanas. As colocações das entrevistadas vão ao encontro do exposto por Natalense (1998) e Neiva e D'Elia (2005), os quais pontuam que o profissional assume uma postura de empreendedor, sendo criativo, ter iniciativa, além de mesclar competências técnicas e humanas, ampliando assim sua dimensão.

No entanto, constataram-se algumas discordâncias nas respostas das entrevistadas acerca das competências, como: comunicação, gestão de pessoas, habilidade com finanças e cálculos, conhecimento de Direito, bom conhecimento de português e produção textual, habilidade com atendimento ao público, administração do tempo, empreendedorismo, indicadas pela entrevistada E. Psicologia, cerimonial, redação oficial e organização de sistemas e métodos, ser atualizado, facilitador, inovador e resiliente, pontuadas pela entrevistada F. Assim como, agilidade, organização do ambiente, planejar, compromisso com o trabalho, buscar realizar o trabalho em tempo hábil e bem executado, gestor, empreendedor, assessor, eficiência e desenvoltura (Entrevistada H); Proatividade, assertividade, destreza, gerenciamento de tempo e descrição gerenciar informações, organizado (Entrevistada J).

Dando continuidade, competências como: ter iniciativa na tomada de decisão, "jogo de cintura", flexibilidade, criatividade, saber lidar com as diversas situações do dia a dia e ainda ser facilitador foram apontadas pelas entrevistadas K e L. Viu-se que muitas das competências mencionadas remetem à competência humana ou pessoal, corroborando o que Bertolino (2002) e Veiga (2007) expuseram ao indicar que o profissional deve atentar-se à capacidade de se ajustar às mudanças, bem como ao conhecimento.

De acordo com os dados apresentados, viu-se que a proatividade e a flexibilidade foram as competências mais abordadas nas entrevistas. Isso encontra amparo nas palavras de Zuin e Findlay (2014, p. 17), as quais indicam que a "natureza do trabalho de secretariado, bem como a forma como eles percebem a si mesmos, estão mudando e podem assumir diferentes formas em diferentes lugares”. Não obstante, o profissional necessita apresentar diferenciais, os quais podem se assentar nas competências Revista de Gestão e Secretariado-GeSec, São Paulo, v. 7, n. 3, p 66-95, set./dez. 2016. 
humanas, traduzindo-se como um destaque desse profissional (Bortolotto \& Willers, 2005; Minarelli, 1995).

Conclui-se que, em se tratando das competências do profissional de SE, os entrevistados evidenciam as habilidades descritas acima- $\mathrm{O}$ perfil do profissional de SE apresenta uma gama de qualidades que propiciam um ambiente e clima organizacionais sadios de trabalho. Esse conjunto de competências oportunizam melhor colocação no mercado de trabalho.

\section{Satisfação e reconhecimento do profissional de Secretariado}

Nesta categoria, investigou-se a satisfação do profissional de SE na sua área de trabalho e se este profissional tem um reconhecimento no mercado e na organização. A entrevistada A afirma que está satisfeita com seu trabalho, e quanto ao reconhecimento, indica que poderia ser mais valorizada, e acrescenta: "Ainda ocorre a situação, como em Roraima, que você praticamente não tem outro campo, a não ser o setor público, que não oferta muitas vagas para o profissional de SE, e o setor privado é escasso". Isso se soma, também, ao relato da entrevistada B, que afirma estar satisfeita,

mas o problema é o local em que vivemos, pois o mercado de trabalho para o profissional de secretariado executivo local é muito restrito, pois não temos empresas privadas que valorizam o secretário como profissional de nível superior em Secretariado Executivo.

As colocações das duas entrevistadas indicam a falta de reconhecimento do profissional de Secretariado Executivo no âmbito das empresas privadas, embora este esteja sedimentando a sua atuação profissional nas competências (Castelo, 2007). Conquanto se tenha a sinalização de que a área de Secretariado Executivo esteja crescendo (Bianchi, Alvarenga \& Bianchi, 2003), talvez essa falta de reconhecimento seja uma singularidade local.

Quando se perguntou à entrevistada C sobre sua satisfação na atividade profissional, percebeu-se que ela se encontra satisfeita, embora quanto ao reconhecimento: "O secretário executivo não tem reconhecimento, e devido as pessoas conhecerem pouco desse profissional, confundem as suas atribuições com a de um Assistente Administrativo". Já a entrevistada D destacou que se sente satisfeita e reconhecida: "Esse profissional tem uma visão global da empresa e, com isso, mantém um relacionamento produtivo". A entrevistada E acrescenta

Revista de Gestão e Secretariado-GeSec, São Paulo, v. 7, n. 3, p 66-95, set./dez. 2016. 
Me sinto valorizada, porque o profissional de Secretariado é uma peça fundamental para o sucesso da organização [...] muitas empresas têm um conhecimento deturpado da profissão, pensam que qualquer pessoa pode exercer a função de SE, e por isso não há reconhecimento.

Ainda nesse contexto, o entrevistado F ressalta que "Sua satisfação é contribuir para a instituição, e que o reconhecimento ainda é pouco porque estamos inseridos numa sociedade que desconhece as atribuições do profissional de Secretariado Executivo". Já a entrevistada G afirma: "Não estou satisfeita devido não exercer a profissão oficialmente, e o profissional de Secretariado Executivo não é reconhecido, e muito menos valorizado, principalmente no que diz respeito ao salário [...] desconhecem as atribuições $[\ldots . .$. ”. Isso se soma à fala da entrevistada $\mathrm{J}$ :

Não estou satisfeita e não é grande o reconhecimento do profissional de Secretariado em Boa Vista, pois acham que o estereótipo deste profissional é somente atender ligações, anotar recados e servir cafezinho [...] sendo que ele é peça fundamental em qualquer organização.

A entrevistada $\mathrm{K}$ acrescenta:

Não me sinto satisfeita e não há reconhecimento em muitos lugares, porque julgam o profissional meramente como uma simples secretária [...] e ainda desconhecem o que realmente o profissional de SE executa no mercado de trabalho.

A entrevistada $\mathrm{H}$ fala que sua satisfação só será completa quando estiver atuando como Secretária Executiva. E acrescenta

O quesito reconhecimento ainda deixa a desejar, inclusive acredito que nós como profissionais e acadêmicos de secretariado devemos divulgar mais a profissão, pois ainda existem muitos gestores que não conhecem o perfil do profissional de SE.

Ainda com relação à satisfação, a entrevistada I destaca que está satisfeita:

E que o reconhecimento vem crescendo cada vez mais, no estado de Roraima, onde o mercado gira em torno do serviço público, são ofertadas cada vez mais vagas para o cargo de Secretário Executivo.

E a entrevistada L pontua: "Estou satisfeita, porque adoro o que faço [...]"; ela procura manter-se atualizada e, quanto ao reconhecimento, a entrevistada indica que existe uma barreira entre a secretária que se dedicava apenas a cuidar da agenda, atender telefonemas e redigir cartas ditadas pelo chefe, e a de hoje em dia, que ocupa uma função bem mais estratégica, atua como assessora e precisa estar mais preparada para desempenhar seu cargo com uma postura mais executiva.

Revista de Gestão e Secretariado-GeSec, São Paulo, v. 7, n. 3, p 66-95, set./dez. 2016. 
De acordo com as entrevistadas, observou-se que sete estão satisfeitas, porém não se sentem reconhecidas; duas estão satisfeitas e sentem-se reconhecidas e três estão insatisfeitas. Houve mudança no perfil do profissional de Secretariado Executivo, exigindo o desenvolvimento de competências (Neiva \& D’Elia, 2005; Bianchi, Alvarenga \& Bianchi, 2003; Castelo, 2007; Bond \& Oliveira, 2009) em função do próprio mercado de trabalho, mas o reconhecimento deste profissional se apresenta em um processo lento. Isso não só impacta no desenvolvimento dos profissionais no mercado de trabalho, mas também na escolha dos jovens à formação de Secretariado Executivo, por saber que a profissão ainda não possui o adequado reconhecimento por parte das empresas.

Muitas das respostas abordam que veem o profissional de SE como meros secretários, sem nenhum tipo de formação, sem um sentido de atuação, e ainda, que muitas organizações não reconhecem o profissional de Secretariado Executivo. As entrevistadas que estão satisfeitas e reconhecidas ressaltam que o reconhecimento cresce a cada momento neste mundo globalizado.

\section{Dificuldades de inserção no mercado de trabalho}

Nas questões 7, 8, 9 e 10 os entrevistados expuseram suas opiniões acerca das dificuldades no mercado de trabalho e os aspectos que não foram desenvolvidos na graduação. Quando questionados sobre as dificuldades encontradas para se inserir no mercado de trabalho, obteve-se: A entrevistada A afirmou que

Não tive dificuldades, quando formada, surgiu um concurso público, no qual me inscrevi me dediquei aos estudos e fui aprovada em primeiro lugar.

Mas acrescenta que

Há dificuldades pela falta de oferta de vagas para o cargo de Secretariado Executivo [...] pela escassez do setor privado no mercado em Roraima.

E a entrevistada B indicou que

O estado de Roraima só tem concurso público que dá oportunidades para atuar como secretárias executivas, e que as empresas privadas não têm um salário digno de nível superior em Secretariado e não tem um reconhecimento para este profissional.

Já a entrevistada $\mathrm{C}$ observa que

Os gestores não reconhecem esse profissional, então é difícil fazê-los entender que há grande diferença em se ter um profissional formado, não uma secretária por nomeação, mas alguém que possa realmente fazer a diferença dentro da empresa [...].

Revista de Gestão e Secretariado-GeSec, São Paulo, v. 7, n. 3, p 66-95, set./dez. 2016. 
Embora a entrevistada $\mathrm{C}$ tenha relatado isso, ela não identificou dificuldade para se inserir no mercado de trabalho, pois em um prazo de seis meses após sua diplomação, começou a atuar no mercado.

Nessa mesma esteira de pensamento, as entrevistadas $\mathrm{D}$ e $\mathrm{K}$ relataram não ter dificuldade para se inserir no mercado de trabalho; indicaram, porém, que o mercado apresenta suas exigências.

A entrevistada E respondeu "Tive dificuldade, porque geralmente para esse cargo por ser uma função de confiança, além da competência é necessária uma indicação". Relembrando que Baggio et al. (2005) assevera que um dos fatores da empregabilidade é a rede de relacionamentos estruturada pelos profissionais. A indicação provém das redes de relacionamentos construídas. E a entrevistada $\mathrm{F}$ destaca que "O início foi difícil pela falta de conhecimento da sociedade a respeito das atribuições do profissional de secretariado".

Na sequência, a entrevistada $\mathrm{G}$ aborda que

Na área privada ainda se encontra dificuldade devido não haver valorização da profissão de Secretariado Executivo, mas na área pública é fácil porque já existe concurso público para o cargo de SE e com isso você não encontra muitas dificuldades.

$\mathrm{Na}$ percepção da entrevistada $\mathrm{H}$ somando com a fala das demais: "Minha dificuldade era o medo de avançar, porém com o tempo você percebe que as coisas são possíveis e que na verdade [...] colocamos dificuldades". Como acrescenta a entrevistada I "Tive dificuldade diante da forte concorrência do mercado de trabalho".

E, na perspectiva da entrevistada $\mathrm{J}$,

Sim houve dificuldade, pois as ofertas de vagas para profissional de secretariado graduado são poucas, e quando aparecem existe uma grande competição por elas, onde quem ganha é quem tem mais experiência de trabalho, pelo fato de ter se formado há muito tempo.

E, a entrevistada L: "Como já estava atuando antes do término da graduação, e já trabalhava como auxiliar administrativo foi apenas um passo não tive muita dificuldade".

Dessa forma pode-se observar que dentre os profissionais de Secretariado Executivo seis entrevistados não sentiram dificuldades em inserir-se no mercado para o qual se formaram e os outros seis tiveram dificuldades para conquistarem uma oportunidade de inserção nas organizações. O profissional de SE enfrenta desafios relativos ao salário visto que alguns dos entrevistados consideram que não é compatível 
com as atribuições, escassez na oferta de vagas principalmente no setor privado, forte concorrência no mercado de trabalho e falta de valorização da profissão.

E, no que diz respeito à questão 8 , a qual versa sobre os aspectos que não foram desenvolvidos na graduação de forma satisfatória e o que eles poderiam ter auxiliado na inserção no mercado de trabalho, a entrevistada A pontuou:

Hoje como profissional percebo que faltou sim o desenvolvimento melhor em algumas disciplinas do curso, mas aprendi a ser autodidata, [...] se eu pudesse diria isso para os acadêmicos, que busquem o conhecimento, e ainda mais, mesmo que estejam cursando uma disciplina de modo satisfatório [...] com certeza, se o acadêmico fizer isso, for desenvolto, e tiver absorvido bem o conhecimento aprendido em sala de aula e fora dela, não deverá encontrar muitas dificuldades no mercado de trabalho, e de fato, são esses os que conseguem a vaga.

Essa colocação vai ao encontro da indicação de Neiva e D’Elia (2005) que sinalizam a busca do aprimoramento do fazer diário do profissional de Secretariado Executivo, assim como Bianchi, Alvarenga e Bianchi (2003) que já indicavam uma postura que transcende apenas o solucionador de problemas. Nesse sentido, a forma como são conduzidas as disciplinas, bem como os objetivos nelas propostos estão diretamente relacionados ao desenvolvimento de competências que traduzem um profissional inovador e visionário (Bianchi, Alvarenga \& Bianchi, 2003; Neiva \& D’Elia, 2005; Castelo, 2007).

Por outro lado, a entrevistada B:

Sim, faltaram primeiro a disciplina de arquivologia deixou a desejar [...] faltou uma disciplina voltada para o relacionamento interpessoal, não teve esse contato com o público [...] faltou a prática, só teve teoria, [...] falta uma atuação não sei se pouco mais da universidade pra mostrar as competências de nível superior de secretariado para as empresas.

Nesta perspectiva a entrevistada C acrescenta, "Sim, com certeza teve muitos, principalmente para raciocínio analítico e crítico [...] não aprendi nada em inglês e o pouco de espanhol, como não desenvolvo, acaba não sendo incorporada à profissão”. E, a fala da entrevistada E: "Sim, houve uma deficiência no ensino de línguas, inglês e espanhol que impediram que pudesse concorrer a vagas em empresas multinacionais, cujo requisito é fluência nos idiomas citados". Dessa forma a entrevistada F: "Sim. deveria ter mais aulas de fotoshop e coreldraw para adquirirmos mais adaptação junto à tecnologia”. E já a entrevistada G destaca: “Sim, a área de informática e área de línguas não foram muito bem desenvolvidas". A entrevistada $K$ afirma "sim, a dificuldade foi 
principalmente na disciplina de cerimonial faltou mais empenho da universidade na teoria e prática".

Ainda sobre aspectos que não foram desenvolvidos na graduação de forma satisfatória e o que poderiam ter auxiliado na inserção no mercado de trabalho, para a entrevistada D, todas as disciplinas foram desenvolvidas satisfatoriamente. Já a entrevistada $\mathrm{H}$ relatou que

[...] todas as disciplinas nos passam um tipo de conhecimento, onde uma pode ser aplicada no mercado e outras não. Na época da graduação uma das disciplinas bem importante era relacionada à metodologia, a mesma não foi bem desenvolvida com a turma.

E, a entrevistada I acrescenta:

[...] o curso tem uma boa base teórica, essencial para ingresso no serviço público. Os fatores que poderiam ser melhores desenvolvidos no curso são mais necessários na atuação do profissional, onde a prática é exigida.

Ainda no contexto, a entrevistada J corrobora:

Acredito que o curso é muito bom e depende muito do aluno, por exemplo na área de línguas, não dá pra ficar só com o conhecimento adquirido na instituição, precisa fazer um curso a parte para poder ter um melhor desempenho, e em relação aos eventos, poderiam fazer mais simulados de situações hipotéticas para o entendimento e prática dos alunos.

Por fim, a entrevistada L ressalta: "Não, vejo o curso abrangente".

$\mathrm{Na}$ percepção dos profissionais de SE percebeu-se que para alguns dos entrevistados faltaram alguns aspectos na graduação que não foram desenvolvidos de forma satisfatória como: disciplinas de línguas, informática, metodologia e outros aspectos que poderiam ter auxiliado no mercado de trabalho. Esse quadro decorre, muitas vezes, de dificuldades por parte dos acadêmicos, e também, por falta de estímulo ofertado pelos professores e curso para que haja o desenvolvimento de características que os profissionais devem ter como: estar orientado para a ação, e fazer acontecer, assim como ter iniciativa pessoal (Baggio et al., 2005; Chiavenato, 2002). Isso fará com que o profissional esteja sempre atualizado e buscando novos conhecimentos para se adequar ao mercado competitivo, reforçando sua postura inovadora e diferenciada (Porter, 1989).

Ao serem questionados sobre os desafios e dificuldades abordadas anteriormente enfrentadas pelo profissional de Secretariado, e o que as universidades poderiam fazer para minimizar as diferenças exigidas, na percepção dos entrevistados, viu-se que a Revista de Gestão e Secretariado-GeSec, São Paulo, v. 7, n. 3, p 66-95, set./dez. 2016. 
consolidação de parcerias entre a universidade e empresas do mercado é a indicação premente na fala dos sujeitos de pesquisa, como segue

Mais parcerias com as empresas pra mostrar o que eles estão colocando no mercado de trabalho que não é um mero técnico, estão saindo pessoas com nível superior, pessoas gabaritadas para poder gerir, assessorar [...];

além disso, é indicado que o curso oferte as disciplinas com profissionais qualificados:

[...] a contratação de professores dedicados à formação profissional de SE, o que não acarretaria o déficit na formação de alguns alunos. Para melhor manter nessa direção sadia, a avaliação docente por parte dos discentes, para que o colegiado do curso verifique o que está em falta, o que está bom e pode melhorar, enfim, corrigir os problemas e melhorar cada vez mais [...].

Vê-se que esses dois pontos, a saber: a qualificação dos docentes e a interação da universidade com o mercado a fim de divulgar e demonstrar a profissão de Secretariado executivo são os dois aspectos apontados pelos sujeitos de pesquisa. Isso ressoa nas falas de Bianchi, Alvarenga e Bianchi (2003), Bond e Oliveira (2009) e ainda Schmitz, Battisti e Santos (2015), os quais indicam que o profissional de SE deve manter-se atualizado e atento às mudanças do mercado; uma vez estruturado o vínculo contínuo entre universidade e mercado. A instituição de ensino necessita fazer esse elo, seja por meio de workshops, fóruns, empresa júnior, estágios e a própria atualização do projeto político pedagógico, com foco no diálogo permanente entre ela e o mercado. Essa postura auxiliará no conhecimento sobre o profissional de SE, e dessa forma fomentará a valorização e o reconhecimento desta profissão no mercado, que também poderá se dar por meio de uma organização formal da categoria, ou seja, um Conselho.

\section{Perfil e competências do profissional de SE na percepção dos gestores de RH}

Nesse quesito, as questões 1, 2, 3 e 4 versam sobre as competências e o perfil exigidos pelas empresas no mercado de trabalho para o profissional de Secretariado Executivo. Conforme a entrevistada 1 aborda a respeito das competências exigidas para o perfil do profissional de Secretariado em que esse profissional deve

assessorar, gerenciar informações, elaborar documentos, coordenar e controlar equipes e atividades, controlar correspondência e organizar eventos e viagens $[\ldots]$ sendo que esse perfil segue as regras propostas pelo MEC.

Segundo a Entrevistada 2 "O profissional de Secretariado tem de ter esmero perfeição e primor em tudo que executa e na maneira como se expressa, interesse e Revista de Gestão e Secretariado-GeSec, São Paulo, v. 7, n. 3, p 66-95, set./dez. 2016. 
responsabilidade [...]" Já as entrevistadas 3 e 4 explicam que o perfil do profissional de SE primeiramente deve: "Ser graduado em Secretariado Executivo, além de expedir documentos, de conhecer sobre arquivo e redação além de secretariar reuniões, fazer o papel de um Assistente Administrativo".

Com relação à questão 2, relacionada ao perfil adequado do profissional de SE desejado no mercado, as entrevistadas 1, 2, 3 e 4 responderam da seguinte forma, respectivamente:

Um profissional proativo, responsável, comunicativo, criativo, relacionamento interpessoal além das competências técnicas e humanas;

[...] Fundamental que esse profissional procure novas visões do mundo, de autoconhecimento e que seja capaz de se valorizar constantemente, seja proativo, flexível e se adapte as mudanças para que seja capaz de vencer no mercado competitivo [...].

Que esse profissional tenha proatividade, agilidade, desenvoltura na comunicação, fluência em espanhol”, finalizando com a indicação de "[...] resolução de problemas, tenha atitude, seja proativo e que tenha flexibilidade.

Em relação às respostas, pode-se notar que as opiniões foram diferentes em alguns aspectos, mas todas concordam que o profissional de secretariado tem de ser um profissional proativo. Percebe-se que essa colocação reflete nas indicações de Neiva e D’Elia (2005) e Nascimento et al. (2005), os quais indicam que o profissional deve ser administrador de sua carreira.

Ao ser perguntado sobre as diferenças do perfil do egresso com o perfil que o mercado deseja e o que fazer para minimizar essa diferença a entrevistada 1 explica que

há diferenças porque antes nomeavam um profissional de SE [...], como Assistente Administrativo e que havia uma certa limitação [...] e hoje que fazem pra minimizar essa diferença é aproveitar muito bem o profissional de SE no órgão, o que antes não acontecia, sendo que o mesmo desempenha muito bem suas funções atendendo às exigências atribuídas pelo gestor.

A entrevistada 2 ressalta:

Sim, o perfil quando graduando é completamente diferente, levando em consideração a discriminação do profissional diante do mercado de trabalho, no futuro, [...] será aquele que vai trabalhar para a empresa e em equipe, assumir riscos moderados e investir [...].

Revista de Gestão e Secretariado-GeSec, São Paulo, v. 7, n. 3, p 66-95, set./dez. 2016. 
Hilsdorf (2008) aponta a dinamicidade da empregabilidade, exigindo do profissional educação continuada e transfiguração das competências essenciais. Assim, a entrevistada 3 diz que

Não, que o mercado não exige tanto, mas que o profissional de secretariado executivo oferece muitas competências boas só que o mesmo não lhe dá a devida oportunidade para que seja explorado suas habilidades.

\section{A entrevistada 4 corrobora que}

Alguns profissionais de SE não possuem fluência em uma segunda língua e, que por muitas vezes, são tímidos e que isso atrapalha o processo de comunicação e o que faria para minimizar essas diferenças realizações de cursos de língua [...] acompanhamento psicológico.

Observa-se que esses gestores de Recursos Humanos valorizam muito a profissão de Secretário Executivo, pois confiam plenamente no desempenho de suas competências, e sabem que eles são muito mais capazes de apenas solucionar problemas que possam acontecer, e que esses profissionais podem agregar às organizações, impactando em seus resultados.

Na questão 5 perguntou-se sobre a chance de um profissional de SE conseguir uma boa colocação no mercado de trabalho. A entrevistada 1 ressalta que "Na instituição faz-se um mapeamento de talentos e verifica a capacidade do profissional de SE [...] e ainda acrescenta uma frase: "quem não é visto não é lembrado por mais que seja um ótimo profissional”. Isso ratifica mais uma vez, a rede de relacionamentos que o profissional deve estabelecer (Minarelli, 1995).

A entrevistada 2 acrescenta:

Para ser um bom profissional não basta ter grandes conhecimentos informáticos, administrar contatos, agendas e/ou serviços, para ter sucesso, o profissional necessita manter-se informado e ter conhecimentos não só sobre o seu trabalho, mas também sobre a empresa só com estas características o profissional de SE será respeitado e valorizado.

Na fala da entrevistada 3:

Não tem um plano de cargos que contemple o Secretário Executivo, devido o mesmo fazer o papel de assistente administrativo dentro da instituição [...] há concurso público”. Já a entrevistada 4 destaca que "As chances são boas visto que o ingresso é feito através de concurso público.

Revista de Gestão e Secretariado-GeSec, São Paulo, v. 7, n. 3, p 66-95, set./dez. 2016. 
Dessa forma, pode-se perceber nas entrevistas que os gestores destacam que esse profissional tem de ter capacidade e possuir algumas características desejáveis (proativo, flexível, facilitador, multifuncional, polivalente dentre outras) para que seja reconhecido na organização e soma-se o fato, segundo duas gestoras, de que a colocação no mercado de trabalho se dá por concurso público.

\section{Oportunidades e desafios para o profissional de SE}

Ao serem questionadas sobre oportunidades e desafios para que esse profissional acompanhe as mudanças do mercado, obtiveram-se as respostas a seguir: A entrevistada 1 pontuou que o profissional "Deve estudar e se qualificar além de fazer suas atividades, tem que acompanhar o perfil, acompanhando a dinâmica do mercado de trabalho". Segundo a entrevistada 2

ambiente empresarial mudou o perfil do profissional de Secretariado, que começou a ter um papel de destaque na empresa, o seu potencial foi reconhecido, criando a possibilidade de construir uma carreira tão promissora como a de qualquer outro executivo.

E ainda afirma que

A transformação nas funções de secretário não aconteceu por acaso, acompanhou a abertura dos mercados, a reengenharia das empresas e a necessidade de profissionais multidisciplinares e com poder de decisão dentro das corporações.

Na década de 1990, Natalense (1998) já indicara a postura empreendedora do profissional de SE; assim como Bortolotto e Willers (2005) que indicam a não limitação desses profissionais em tarefas de rotina em um ambiente organizacional.

E, já a entrevistada 3 respondeu o seguinte

Esse profissional precisa dedicar-se ao conhecimento do trabalho que irá realizar e deve usar sempre o bom senso e o equilíbrio para que possa transmitir confiança e capacidade de solucionar problemas mantendo sempre aberto para novas aprendizagens na execução das atividades que lhe são confiadas, sempre se atualizando, pois com isso obterá êxito para acompanhar as mudanças do mercado.

E a entrevistada 4 ressalta: "Necessário estar sempre estudando e atualizando seus conhecimentos além de contribuir para o destaque nos seus mercados de atuação”. Peres (2005) já colocara que os profissionais do século XXI necessitam ter verdadeira formação naquilo que se dispuseram a trabalhar, confirmando também as colocações de

Revista de Gestão e Secretariado-GeSec, São Paulo, v. 7, n. 3, p 66-95, set./dez. 2016. 
Arruda (2010), o qual indicara que o conhecimento é essencial ao crescimento dos profissionais no mercado de trabalho.

Portanto, na percepção dos gestores acerca das oportunidades e desafios observou-se a abrangência das oportunidades, embora ainda existam obstáculos a serem superados. Vale ressaltar a necessidade de que o profissional de Secretariado Executivo esteja atualizado, buscando novos conhecimentos e se qualificando para que possa acompanhar as mudanças do mercado.

\section{Importância do profissional de secretariado para o mercado de trabalho}

Ao ser perguntado sobre o grau de importância do profissional de SE para os gestores nas organizações, a entrevistada 1 destacou que o profissional de SE deve ter

[...] grau de excelência, [...] além deste profissional [...] ser polivalente e multifuncional característica essas que é de fundamental importância no mundo globalizado ao qual fazemos parte e que fazem a grande diferença no perfil profissional, onde terá muito espaço e reconhecimento para conquistar.

A entrevistada 2 ressalta "O profissional de Secretariado de hoje é muito mais importante e tem tarefas mais complexas num lugar de confiança no seio de qualquer empresa, sendo um "braço direito" para o executivo[...]". Como se percebe ainda na fala da entrevistada 2 o profissional de secretariado assume o papel de assessor, agregando para o alcance dos objetivos da organização, e auxiliando nas tomadas de decisão.

Assim a entrevistada 3 ressalta que

Além das mudanças frequentes no mercado de trabalho o secretário é muito importante porque nem todo gestor tem a habilidade que um profissional de SE tem como: saber se impor, se expressar, contribuir para organização de um modo facilitador.

E a entrevistada 4 corrobora "Suma importância, visto que este profissional que viabiliza o funcionamento dentro das organizações". Esses relatos reforçam as colocações de Durante e Pontes (2014), os quais indicam a necessidade de investigação e produção intelectual na área de Secretariado a fim de se solidificar um corpus de estudo além de consolidar a identidade do profissional dessa área.

Constatou-se com base nas entrevistas que o profissional de Secretariado Executivo é fundamental na organização devido à flexibilidade de suas competências e atribuições. São profissionais capazes de identificar problemas e resolvê-los, facilitando 
o alcance dos objetivos da organização, só que para isso deve ter constante qualificação e aperfeiçoamento do seu conhecimento neste mundo globalizado.

\section{CONSIDERAÇÕES FINAIS}

Em decorrência da alta competitividade o profissional de SE deve acompanhar as alternâncias para adequar seu perfil às exigências do mercado de trabalho, que será mais um fator determinante para sua inserção e permanência no mundo do trabalho. Neste contexto, o presente trabalho se propôs a verificar as dificuldades encontradas por profissionais de Secretariado Executivo acerca de sua inserção no mercado de trabalho de Boa Vista. Os resultados evidenciaram que as dificuldades de inserção no mercado de trabalho, pela percepção dos profissionais de SE são: escassez de vagas no setor privado em Roraima; baixa remuneração, ausência de reconhecimento por parte dos gestores; e falta de conhecimento de suas atribuições. Quanto à percepção dos gestores de RH aqui investigados, viu-se que eles indicam que a polivalência pode garantir a esses profissionais a empregabilidade; percepção esta distinta dos profissionais de SE. Essa dissonância pode gerar mais discussões ao se avaliar o papel do profissional de Secretariado Executivo no mercado de trabalho.

No que se refere a limitações da pesquisa, sendo esta qualitativa, não se pode ter os dados como conclusivos, tampouco inferir generalizações; isso se deve, também, em função de amostragem não aleatória. A partir dos resultados encontrados, percebe-se que essa pesquisa contribuiu para o enriquecimento da área de Secretariado Executivo, por meio da percepção dos profissionais de SE e dos gestores de RH acerca dos seguintes assuntos: dificuldades de inserção do mercado do trabalho, satisfação, reconhecimento, importância, perfil e competências desse profissional, como também, no sentido de incentivar os estudos no mercado de trabalho, conhecendo as competências profissionais.

Revista de Gestão e Secretariado-GeSec, São Paulo, v. 7, n. 3, p 66-95, set./dez. 2016. 


\section{REFERÊNCIAS}

Arruda, Adriano (2010). Mercado de Trabalho. Recuperado em 5 de junho, 2013, de <http://www.artigonal.com/carreira-artigos/adriano-arruda-mercado-de-trabalho1722942.html.>

Baggio, Letícia et al. (2005). Como manter a empregabilidade em tempos de crise. Recuperado em 12 de junho, 2013, de <http://www.fsh.edu.br/revista/artigo1-comomanter-empregabilidade.pdf.>.

Bertolino, Valdessara (2002). O profissional multifuncional. Publicado em: 21 de setembro de 2002. Recuperado em 12 de junho, 2013, de <http://www.secretariando.com.br/carreira/carr-30.htm.>.

Bianchi, Anna Cecilia de Moraes; Alvarenga, Marina \& Bianchi, Roberto (2003). Orientação para estágio em secretariado: trabalhos, projetos e monografias. São Paulo: Pioneira Thomson Learning.

Bond, Maria Thereza \& Oliveira, Marlene de (2009). Manual do profissional de secretariado, vol. 3: secretário como cogestor. Curitiba: Ibpex. Recuperado em 22 de outubro, 2013, de <http:// books.google.com.br>.

Bortolotto, M., \& Willers, E. (2005). Profissional de Secretariado Executivo: Explanação das principais características que compõem o perfil. Revista Expectativa, 4(4), 45-56.

Carvalho, Antonio Pires de \& Grisson, Diller (2002). Manual do secretariado executivo. São Paulo: D’Livros.

Castelo; Márcia Janaina (2007). A formação acadêmica e a atuação profissional do Secretário Executivo. Recuperado em 2 de outubro, 2013, de <http://www.fenassec.com.br/consec_3lugar.pdf.

Chiavenato, Idalberto (2002). Carreira e competência: gerenciando o seu maior capital. São Paulo: Saraiva.

D’Elia, Maria Elizabete (1997). Profissionalismo: não dá para não ter. São Paulo: Editora Gente.

Durante, Daniela Giareta \& Pontes, Emiliano Sousa (jan./abr. 2015). Produção intelectual em Secretariado Executivo: estudo na Revista de Gestão e Secretariado (GeSec). Revista de Gestão e Secretariado - GeSec, São Paulo, vol. 6, n. 1, pp. 23-47.

Fachini, Maurício Vitório (2009). Novo mercado de trabalho para um novo profissional. Recuperado em 12 de julho, 2013, de http://www.artigonal.com/carreiraartigos/novo-mercado-de-trabalhopara-um-novo-profissional-792001.html. 
Fleury, Maria Tereza Leme \& Sarsur, Amyra Moyzes (2007). Nenhum a menos: desvendando conceitos sobre gestão por competências. In: Administração com arte: experiências vividas de ensino-aprendizagem. Org: Eduardo Davel, Sylvia Constant Vergara e Djahanchah Philip Ghadiri. São Paulo: Atlas.

Hilsdorf, Carlos (2008). O que é empregabilidade? Recuperado em 13 de julho, 2013, de <http://www.administradores.com.br/informe-se/artigos/o-que-eempregabilidade/31256/>.

Maçaneiro, Marlete Beatriz \& Kuhl, Marcos Roberto (dez. 2013). Estado da arte e o rumo do conhecimento científico em Secretariado Executivo: mapeamento e análise em áreas de pesquisa. Revista de Gestão e Secretariado - GeSec, São Paulo, vol. 4, n. 3, pp. 157-188.

Minarelli, José Augusto (1995). Empregabilidade: O caminho das pedras. São Paulo: Editora Gente.

Nascimento, Arielly et al. (2005). Carreira e empregabilidade na área secretarial. $\begin{array}{lllll}\text { Recuperado em } 13 \text { de } & \text { julho, }\end{array}$ http://erevista.unioste.br/index.php/expectativa/article/view/408.

Natalense, Liana (1998). A secretária do futuro. São Paulo: Qualitymark.

Neiva, Edméa Garcia \& D’Elia, Maria Elizabete Silva (2005). Secretária Executiva. São Paulo: IOB Thomson.

Nonato Júnior, Raimundo (2002). Autogestão e gestão do conhecimento em Secretariado. Monografia (Graduação em Secretariado Executivo). Universidade Federal do Ceará - UFC. Fortaleza.

Oliveira, Silvio Luiz de (2002). Tratado de metodologia científica: projetos de pesquisas, TGI, TCC, monografias, dissertações e teses. São Paulo: Pioneira Thomson Learning.

Peres, Angelo (2005). O mundo do trabalho e a empregabilidade. Recuperado em 13 de julho, 2013, de <http://internativa.com.br/artigo_rh_06.html>.

Planalto.gov.br. (19 de junho de 2014). www.planalto.gov.br. Fonte:

www.planalto.gov.br:http://www.planalto.gov.br/ccivil_03/Leis/L7377consol.htm

Porter, Michael (1989). Vantagem competitiva: criando e sustentando um desempenho superior ( $35^{\mathrm{a}}$ reimpressão). Rio de Janeiro: Elsevier.

Pringle, R. (1989). Secretaries talk: sexuality, power and work. London: Verso.

Prodanov, Cleber Cristiano (2009). Metodologia do trabalho científico: métodos e técnicas de pesquisa e do trabalho acadêmico. Novo Hamburgo: Feevale.

Revista de Gestão e Secretariado-GeSec, São Paulo, v. 7, n. 3, p 66-95, set./dez. 2016. 
Roesch, Sylvia Maria Azevedo (2005). Projetos de estágio e de pesquisa em administração: guia para estágios, trabalhos de conclusão, dissertações e estudo de caso. São Paulo: Atlas.

Rosa, Jaqueline Silva (2007). A dinâmica das competências coletivas em redes de cooperação. Dissertação de mestrado (Programa de pós-graduação em Administração). Universidade do Vale do Rio dos Sinos- Unisinos. São Leopoldo (RS).

Saviani, José Roberto (1997). Empresabilidade: como as empresas devem agir para manter em seus quadros elementos com alta taxa de empregabilidade. São Paulo: Makron Books.

Schmitz, Caroline Jane; Battisti, Patricia Stafusa Sala \& Santos, Sandra Regina Fuhr (maio/ago.2015). Uma análise da consultoria secretarial como novo nicho de mercado e como disciplina nos cursos de Secretariado Executivo. Revista de Gestão e Secretariado - Gesec. São Paulo, vol. 6, n. 2, pp. 19-43.

Thurloway, L. (2004). Silent evolution or quiet extinction: skill and the secretarial labour process. (Unpublished Doctoral Dissertation) Henley Management College.

Veiga, Denise Rachel (2007). Guia de Secretariado: técnicas de comportamento. São Paulo: Érica.

Zuin, Debora Carneiro \& Findalay, Patricia (set./dez.2014). Reflexões sobre o trabalho secretarial e questões para futuros estudos: Uma contribuição conceitual. Revista de Gestão e Secretariado - Gesec, São Paulo; vol. 5; n.3; p.28-48. 